\title{
Equilibrium response of thermohaline circulation to large changes in atmospheric $\mathrm{CO} 2$ concentration
}

\section{Climate Dynamics (2003) 20:759-773}

Figure 7 shown below replaces Fig. 7 of the paper entitled "Equilibrium response of thermohaline circulation to large changes in atmospheric $\mathrm{CO}_{2}$ concentration". The time series of the intensity of Atlantic thermohaline circulation from the $4 \mathrm{xC}$ experiment in the original version of Fig. 7 is in error. It indicated incorrectly that the intensity of the thermohaline circulation (THC) becomes negative during the period between model years 500 and 1300 of the time integration. Although the intensity decreases to $\sim 2$ Sverdrup (Sverdrup $=10^{6} \mathrm{~m}^{3 \mathrm{~s}-1}$ ) between the $300^{\text {th }}$ and $900^{\text {th }}$ year as indicated in the revised Fig. 7 shown below, it never becomes negative throughout the course of the $4 \times \mathrm{C}$ time integration. The discussion of the $4 \times \mathrm{C}$ time series in the published paper is consistent with the corrected time series in new Fig. 7. The time series from other time integrations (i.e., control, $2 \times \mathrm{C}$, and $1 / 2 \times C)$ are correct, and remain unchanged in the revised figure.

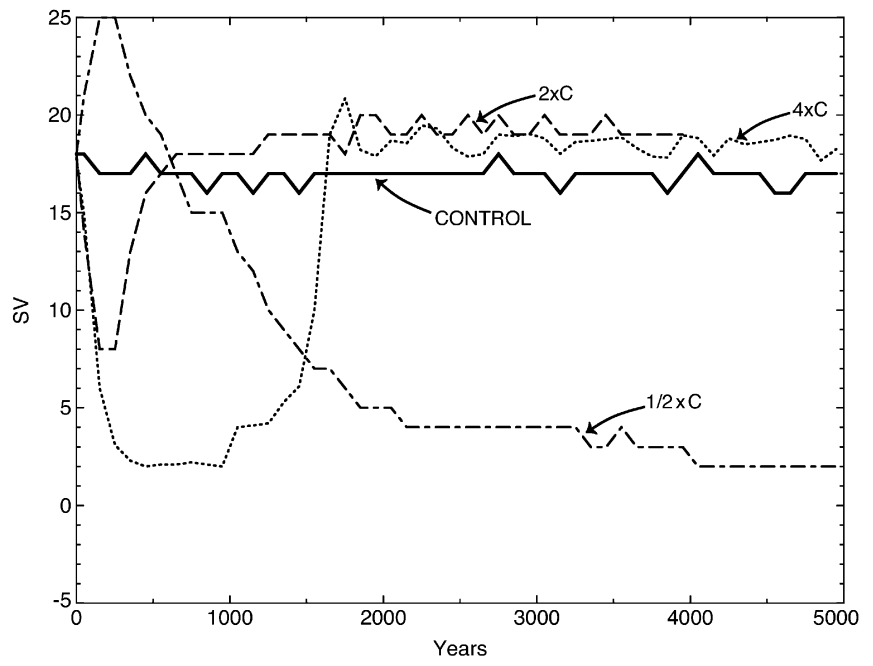

Fig. 7 The temporal variation of the 100-year mean intensity of the THC in the Atlantic Ocean. Solid line: control. Dashed line: $2 \times \mathrm{C}$. Dotted line: $4 \times C$. Dash-dotted line: $1 / 2 \times C$. Here, the intensity of the THC is defined as the maximum value of its streamfunction of the deep overturning circulation in the North Atlantic Ocean. Units are in Sverdrup $\left(=10^{6} \mathrm{~m}^{3} \mathrm{~s}^{-1}\right)$

The online version of the original article can be found at http:// dx.doi.org/10.1007/s00382-002-0302-4

\section{R. J. Stouffer $(\bowtie)$}

Geophysical Fluid Dynamics Laboratory/NOAA,

PO Box 308, Forrestal Campus, Princeton University,

Princeton, NJ 08542, USA

E-mail: Ronald.Stouffer@noaa.gov

S. Manabe

Program in Atmospheric and Oceanic Sciences,

Princeton University, PO Box CN710, Sayre Hall,

Forrestal Campus, Princeton, NJ 08544-0710, USA 